\title{
A Novel Outreach To High School Students By Teaching Them The Engineering Skills In A Project-Based Approach
}

\author{
Bahram Asiabanpour, Texas State University- San Marcos, USA
}

\begin{abstract}
In this paper a novel outreach approach to high school students to familiarize them with engineering functions and methods are explained. In this approach students participated in a seven days research camp and learned many engineering skills and tools such as CAD solid modeling, finite element analysis, rapid prototyping, mechanical tests, team working, and communication skills under a project-based bridge design research project. End of the program survey results showed a good understanding about the engineering skills and functions and a high degree of satisfaction among participants.
\end{abstract}

Keywords: High school, outreach, teaching engineering, project-based

\section{INTRODUCTION}

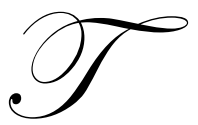

he National Science Board in a recent report identified three key challenges in engineering education: First, in response to global change that has encouraged US companies to outsource their production and service units to overseas, the Board recommended that the education and skills of U.S. engineers should change in a way that cannot be easily replaced by engineers in other countries. Some of important characteristics of the US engineers should be ability to solve "complex interrelationships" and "encompass human and environmental factors"[1]. According to a report of the national innovation initiative summit, Innovate America, "innovation will be the single most important factor in determining America's success trough the $21^{\text {st }}$ century." [2] The second challenge is to overcome inaccurate perceptions of engineering among high school students and their parents as well as their teachers. Surveys show that the general public is not fully aware of engineering's role in "improving health, the quality of life, and the environment." This inaccurate public belief has resulted in the current situation that only those students who are good at math and science and like working with objects rather than people come to engineering programs and those who like team working and finding solutions for social problems have been alienated from engineering programs. "As a result, many students, especially women and minorities, cannot see themselves as engineers."[1] The third challenge is retention of engineering students who initially showed interest to engineering. Some of these dropout students, with higher rates from women and minority groups, were good students, but because of poor performance in "their first math courses," "lack of role models," and "perceptions of a too competitive and uncaring environment" abandoned engineering programs. According to this report "retention of engineering students is a system problem that begins before college." [1] Manufacturing engineering program at Texas State has very similar problematic patterns. The numbers of female students in engineering is very low (currently about 5\%). Also, since 2000 the percentage of Hispanic students in manufacturing engineering program has dropped significantly (from $36 \%$ in 2000 to $21 \%$ in 2006). The fact is that many students and their parents are unaware that the engineering profession offers well paying jobs. According to Salary.com website, in zip code 78666 (San Marcos, TX), a new manufacturing engineering graduate, right out of college with no years of work experience makes $\$ 40 \mathrm{~K}$ to $\$ 55 \mathrm{~K}$ (only base salary without bonus and benefits).

To address the serious problems of misconceptions about engineering as well as the problems of low participation of underrepresented groups and women in engineering, a novel outreach program at Texas State University was conducted. The objectives of this program were to: 
- $\quad$ Attract more underrepresented students to science programs

- $\quad$ Attract more underrepresented and female students to engineering programs

- $\quad$ Familiarize high school students and teachers with engineering concepts and tools

- $\quad$ Teach scientific and technological concepts to high school students by use of hands-on engineering skills in a fun, competitive, and team working environment

- $\quad$ Reach out to high school students and make them aware of engineering programs

The original idea of this program came from an experience at the University of Colorado- Boulder, where they have implemented a very successful program in improving the retention rate of students in the engineering programs by offering a First-Year Engineering Projects (FYEP) course. In this course, teams of students design, build, and test a product based on a customer's need [4]. In the program proposed for this proposal, a similar teambased and open-ended project will be offered to a limited number of high school students to learn, design, prototype, test, compete, and present in the form of one week research camp.

\section{METHOD}

This research outreach project entitled "A river runs through us ${ }^{1}$. So, who's building the bridges for us?" was presented for 16 high school students (4 each from grades $9,10,11$, and 12) who participated in a seven-day research camp distributed over seven consecutive Saturdays. The goal of this project was to introduce new engineering tools and methods to high school students and specifically historically underrepresented minorities and women. Participating students included fourteen male and two female students comprising six white, six Hispanic, one African-American, and three Asian-American students.

Under this research program students initially learned the following engineering and science related topics:

- $\quad$ Computer Aided Design (CAD) for solid modeling and fundamentals of design

- $\quad$ Finite Element Analysis (FEA)

- $\quad$ Rapid Prototyping (RP) software and equipment

- $\quad$ Physical and mechanical properties of materials, standards, testing tools and methods

- $\quad$ Team working, project management, and communication skills

The participating students were then assigned a design project summarized as follows: "The City of San Marcos, Texas, is planning to build and install a series of pedestrian bridges over the San Marcos River to attract more tourists and visitors to the river park areas. Your task is to seek inspiration from the world's most famous bridges such as the Golden Gate Bridge (San Francisco) or the Brooklyn Bridge (New York City), and then to design, build, and make a landscape for a small bridge prototype for the city of San Marcos. The beauty of the bridge and the load/weight ratio will be the main factors in selecting the best design."

The students studied classical bridge designs and the applications for each. Once a basic bridge type was selected, the students used Inventor Autodesk software to design the bridge.

Then the bridges designed by this software, were subjected to simulated loads using Finite Element Analysis (FEA) software (Ansys) to determine if it would be strong enough for the projected loads. Once a bridge design passed the simulated strength test, the design was transferred to the ZEdit software for adding color and texture, and finally a model bridge was built by the Zcorp 450 rapid prototyping machine. This model was then completed by landscaping. Students also received an overview of different mechanical tests. The overview included theory, standard, equipment, and test method for tension, compression, shear, impact, and fatigue tests. For the hands-on activity in this section, instead of breaking their model bridge, they tested smaller sample parts. The Figure 1 illustrates some of the activities in this program. At the end of the program, students demonstrated their bridges, landscapes, and posters for an engineering day open house in the school of engineering and hundreds of high school student visitors observed their work. Later, all bridges, landscapes, and posters were transferred to San Marcos high school for another events including best bridge design competition to be voted by the entire school. Also, camp

\footnotetext{
${ }^{1}$ 2007-2008 Texas State University Common Experience, The Water Planet: A River Runs Through Us
} 
participants were taken to the Capital best robotics competition to observe the competition to be encouraged for offering a team in 2009 competition.

\section{EVALUATION METHOD}

Pre- and post-program surveys were conducted for all participants. In pre-program survey, students were asked about their understanding about engineering functions, their interest in higher education in engineering and science programs, and their skills levels in each topic to be covered during the research camp (Appendix A). Post program survey included similar questions as pre-program survey plus some additional questions regarding their degree of satisfaction of this research camp (Appendix B). Paired t-test statistical tool was used to compare the quantitative sections of the pre/post surveys (Appendix C).

\section{RESULTS}

Results illustrated that in the areas of technical tools and methods (CAD, FEA, RP, mechanical properties, and tests), students' knowledge and skills increased significantly. Also, 100\% of participants expressed that they would participate again in similar programs and they would recommend it to a friend. Also, students' interest in pursuing higher education in science and engineering increased although the increase was not statistically significant.

Additionally, reviewing their qualitative questions in post-research survey shows that, unlike pre-research survey, they had much better understanding about the engineering tasks and functions and the level of overall satisfaction about the camp was considerably high (Appendix D and E).

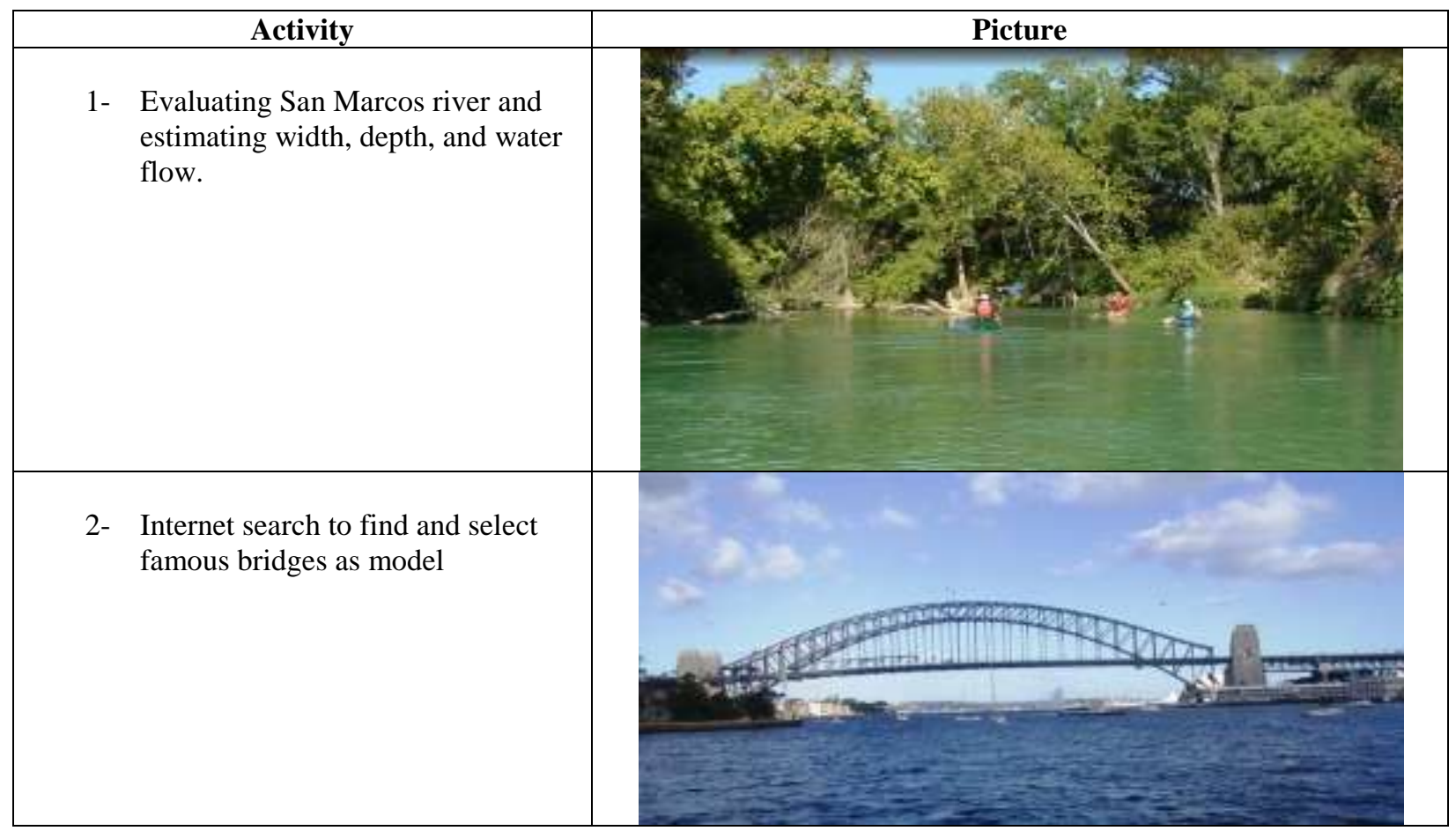

Figure 1. Research activities in the high school outreach research camp 


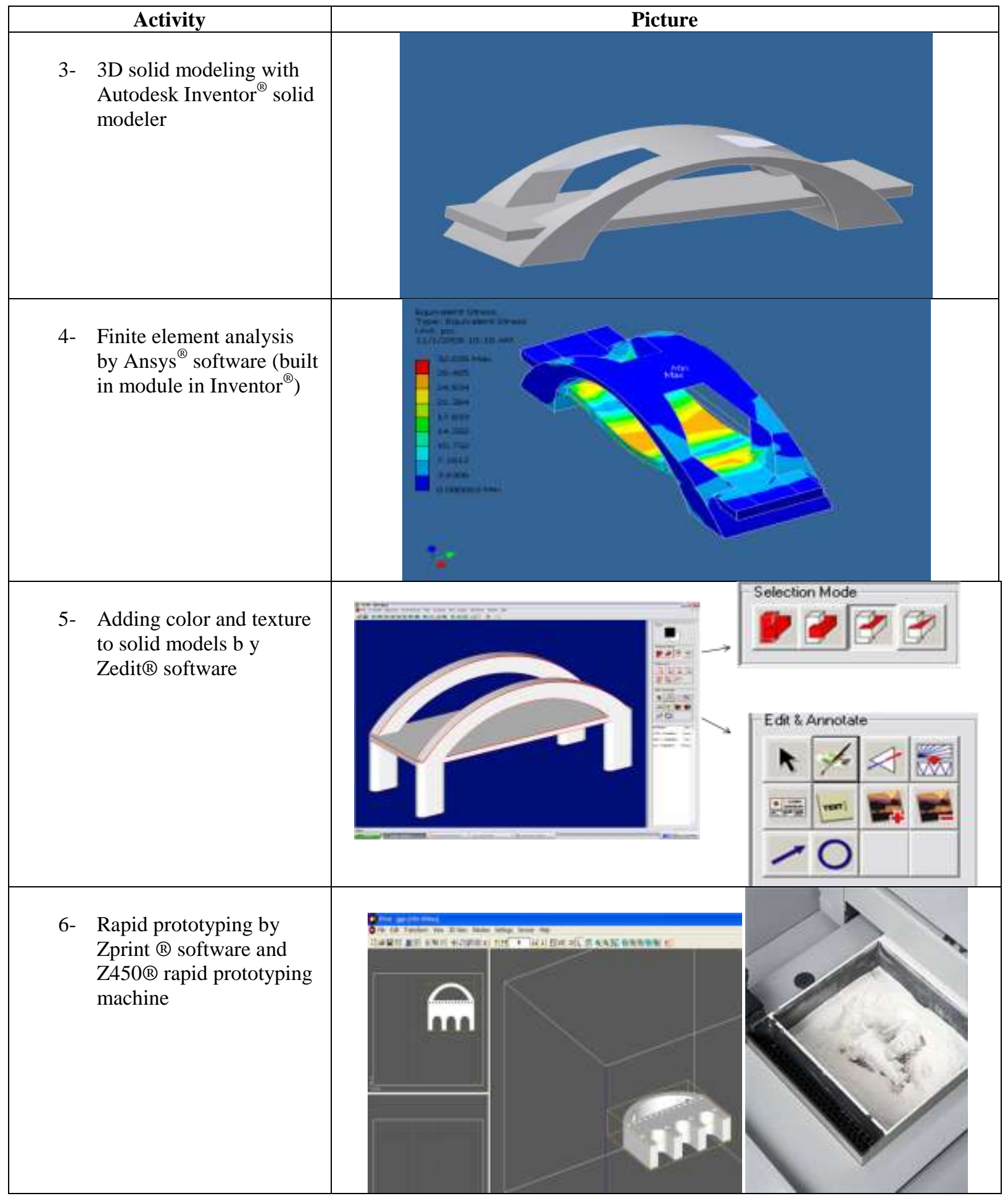

Figure 1. Research activities in the high school outreach research camp (Cont.) 


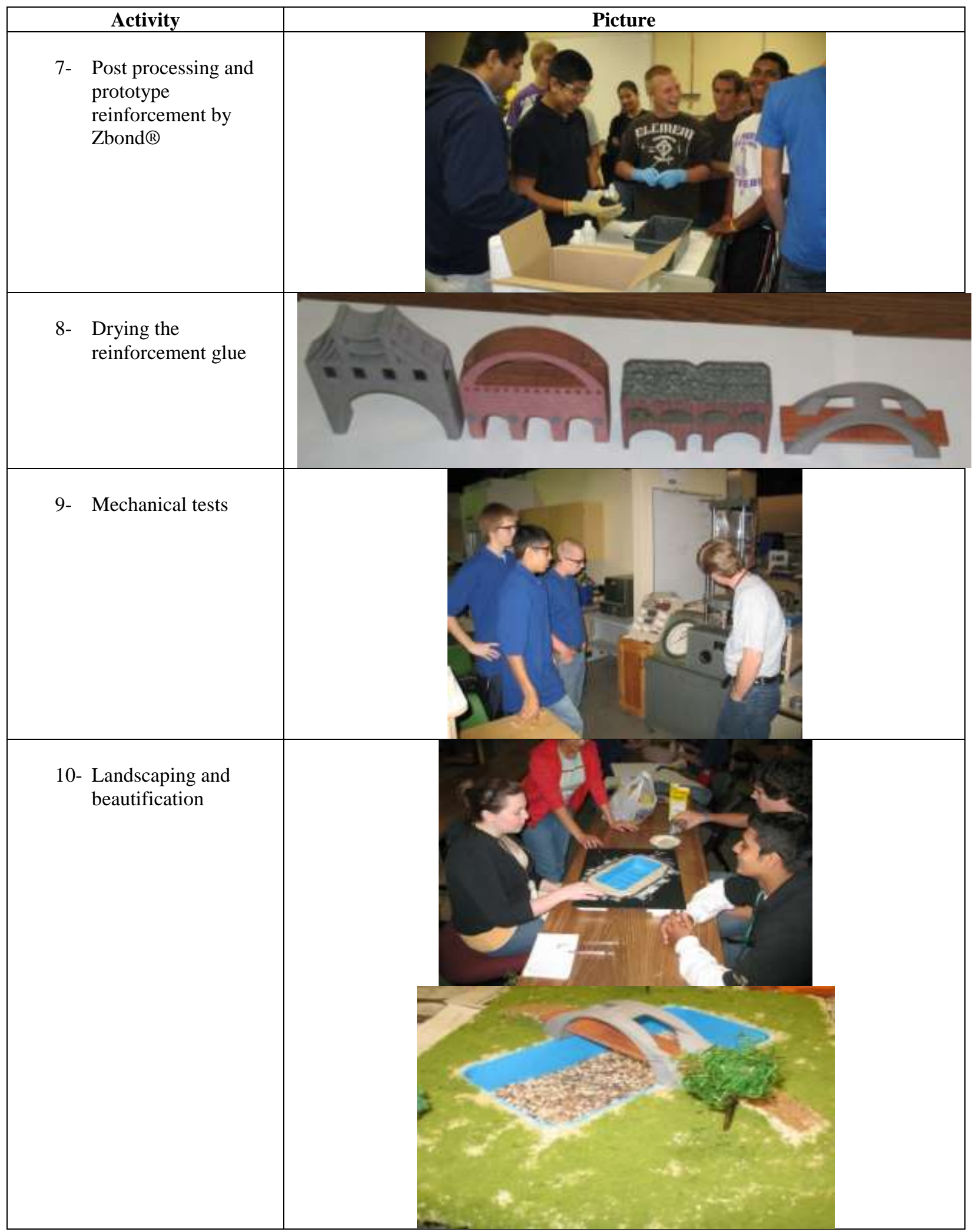

Figure 1. Research activities in the high school outreach research camp (Cont.) 


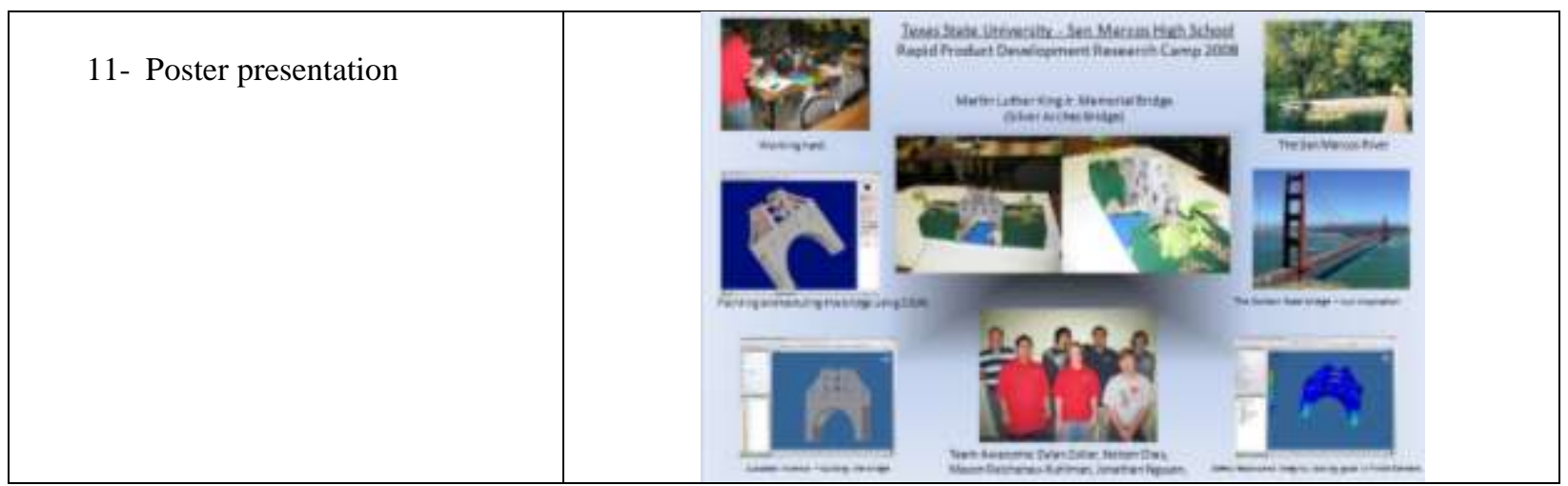

Figure 1. Research activities in the high school outreach research camp (Cont.)

\section{CONCLUSION AND DISCUSSION}

This program was overall a big success as it familiarized a group of students with engineering tools and methods in a hands-on approach and the work was exposed to hundreds of more students (high school student visitors from Austin area on engineering day and San Marcos high school students). To explain the reason that the students' interest in pursuing higher education in science and engineering "increased although the increase was not statistically significant" is that this group was not some random selected students from the entire school population. In contrast, they were all volunteers with good grade standing. This type of students usually have good plan about their higher education and career from their early years of high school.

A few positive indirect consequences of this research camp are that in 2009 the San Marcos high school robotic team, including some of the camp participants, participated in the Capital Best Robotic competition for the first time and ranked $5^{\text {th }}$ among 26 teams and reached to State level finals. Also this high school is in the process of adding a three year engineering courses path in their program.

The Ingram School of Engineering is currently expanding its outreach to additional local high school districts in central Texas under different programs such as Project Lead The Way, collaboration with E3 alliances institution, 2+2 degree program agreement with community colleges around the state, and sponsorship of Capital BEST robotics teams at the junior high and high school levels and First Lego League teams at lower levels.

\section{AUTHOR INFORMATION}

Dr. Asiabanpour is an associate professor of manufacturing engineering at Texas State University. He has published several journal and conference papers in Rapid Prototyping, CAD/CAM, and Micro Assembly. He designed and has taught four new senior-level courses in manufacturing engineering program including capstone senior design. He has been very successful in involving undergraduate students in his research and publications. He has also enlisted the support of local industries in his teaching and research activities. Dr. Asiabanpour is member of the Society of Manufacturing Engineers (SME) and the Institute of Industrial Engineers (IIE), American Society of Engineering Education (ASEE).

\section{REFERENCES}

1. Moving forward to improve engineering education, National Science Foundation publication, 2007.

2. The national innovation initiative summit, Innovate America.

3. Office of institutional research, Texas State University- San Marcos

4. $\quad$ Froyd, J. E., Ohland, M. W., Journal of Engineering Education 94, 147 (2005).

5. Weis, S., Yakubovsky, M., Bittle, B., Cote, R., Kelly, J., "Integrating Engineering Ideas into High School and Middle School Curricula", Proceedings of the 2009 ASEE Gulf-Southwest Annual Conference - Baylor University, 2009.

6. Peterson, L., Tiernan, C., Broussard, L., "Girlgeneering vs. Entry to Engineering: Engineering Outreach Program Comparison of a Girls-Only vs. Co-Ed Engineering Summer Camp", Proceedings of the 2009 ASEE GulfSouthwest Annual Conference - Baylor University, 2009. 
APPENDIX A: Pre-research camp survey

$\begin{array}{lllllll}\text { Grade: } 9 & 10 & 11 & 12 & \text { Gender: } M & \text { F }\end{array}$

1- How familiar are you with engineering tasks and functions as a career?

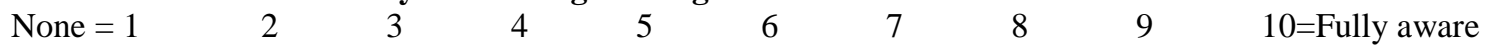

2- How familiar are you with manufacturing engineering tasks and functions as a career?

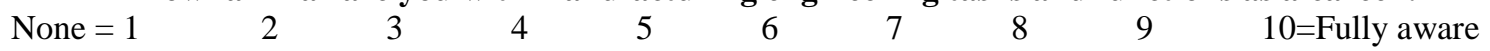

3- How familiar are you with Computer Aided Design and 3 dimensional solid modeling?

Never heard $\begin{array}{llllllllll}1 & 2 & 3 & 4 & 5 & 6 & 7 & 8 & 9 & 10=\text { I'm Expert }\end{array}$

4- How familiar are you with Finite Element Method software and its applications?

Never heard $=\begin{array}{llllllllll}1 & 2 & 3 & 4 & 5 & 6 & 7 & 8 & 9 & 10=\text { I'm Expert }\end{array}$

5- How familiar are you with Rapid Prototyping technologies and their applications?

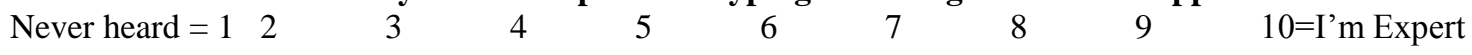

6- How familiar are you with standards and tools for measuring mechanical properties of a part?

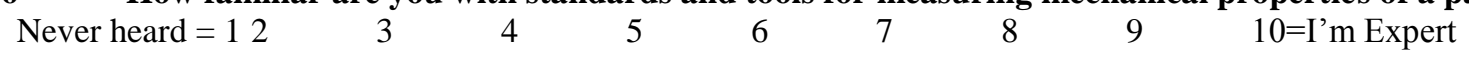

7- How likely it is that you continue your higher education?

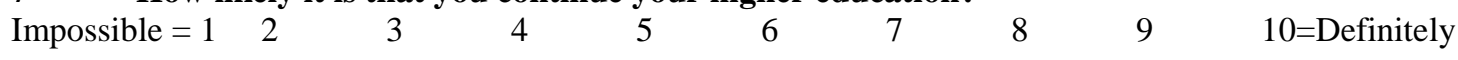

8- How likely it is that you continue your higher education at Texas State?

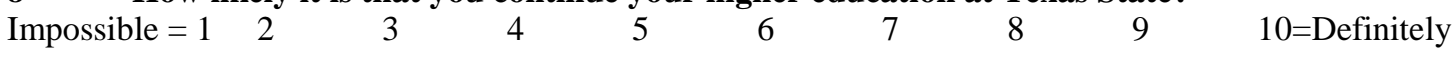

9- How likely it is that you continue your higher education in the field of science (Mathematics, Chemistry, Physics, Biology) or engineering?

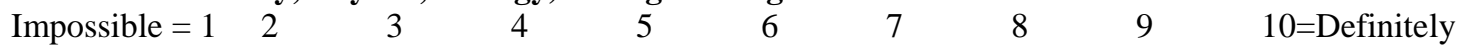

10- How likely it is that you continue your higher education in the field of manufacturing engineering?

Impossible $=\begin{array}{llllllllll}1 & 2 & 3 & 4 & 5 & 6 & 7 & 8 & 9 & 10=\text { Definitely }\end{array}$

11- Describe your understanding about the functions and tasks of the manufacturing engineers and engineers in general? 


\section{APPENDIX B: Post-research camp survey}

All questions listed in pre-research camp survey (Appendix A) plus the following additional questions:

1- Would you recommend this to other friends? Yes/No

2- $\quad$ Would you participate in similar camp (in different engineering areas) in the same format of this camp?
No way $=$

3- $\quad$ Tell us about this research camp. How did you like this research camp?

4- $\quad$ Based on your research experience of this camp, describe your understanding about the functions and tasks of the manufacturing engineers and engineers in general.

\section{APPENDIX C: Pre/Post-research camp surveys data analysis by paired t-test}

Data was processed based on 11 valid answers for average for each grade (e.g., nine graders, ten graders, etc.) as identifying individual students were not possible but it was possible to find out in what grade they are in.

1- How familiar are you with engineering tasks and functions as a career?

\begin{tabular}{|l|c|c|c|}
\hline & Pre & Post & Difference \\
\hline Average & 4.08 & 6.71 & 2.63 \\
\hline Standard Deviation & & & 1.93 \\
\hline $\mathbf{t}$ & & & 4.17 \\
\hline Lower Bound & & & -1.40 \\
\hline Upper Bound & & & 6.65 \\
\hline
\end{tabular}

2- How familiar are you with manufacturing engineering tasks and functions as a career?

\begin{tabular}{|l|c|c|c|}
\hline & Pre & Post & Difference \\
\hline Average & 3.56 & 6.69 & 3.13 \\
\hline Standard Deviation & & & 2.14 \\
\hline t & & & 4.17 \\
\hline Upwer Bound & & & -1.33 \\
\hline
\end{tabular}

3- How familiar are you with Computer Aided Design and 3 dimensional solid modeling?

\begin{tabular}{|l|c|c|c|}
\hline & Pre & Post & Difference \\
\hline Average & 3.13 & 7.04 & 3.92 \\
\hline Standard Deviation & & & 1.42 \\
\hline L & & & 4.17 \\
\hline Upper Bound & & & 0.95 \\
\hline
\end{tabular}

4- How familiar are you with Finite Element Method software and its applications?

\begin{tabular}{|l|c|c|c|}
\hline & Pre & Post & Difference \\
\hline Average & 1.88 & 5.81 & 3.94 \\
\hline Standard Deviation & & & 1.74 \\
\hline t & & & 4.17 \\
\hline Lower Bound & & & 0.32 \\
\hline Upper Bound & & & 7.56 \\
\hline
\end{tabular}


5- How familiar are you with Rapid Prototyping technologies and their applications?

\begin{tabular}{|l|c|c|c|}
\hline & Pre & Post & Difference \\
\hline Average & 1.98 & 7.46 & 5.48 \\
\hline Standard Deviation & & & 1.90 \\
\hline t & & & 4.17 \\
\hline Lower Bound & & & 1.52 \\
\hline Upper Bound & & & 9.44 \\
\hline
\end{tabular}

6- How familiar are you with standards and tools for measuring mechanical properties of a part?

\begin{tabular}{|l|c|c|c|}
\hline & Pre & Post & Difference \\
\hline Average & 4.13 & 7.88 & 3.75 \\
\hline Standard Deviation & & & 1.55 \\
\hline $\mathbf{t}$ & & & 4.17 \\
\hline Lower Bound & & & 0.51 \\
\hline Upper Bound & & & 6.99 \\
\hline
\end{tabular}

7- How likely it is that you continue your higher education?

\begin{tabular}{|l|c|c|c|}
\hline & Pre & Post & Difference \\
\hline Average & 9.92 & 9.29 & -0.63 \\
\hline Standard Deviation & & & 0.98 \\
\hline $\mathbf{t}$ & & & 4.17 \\
\hline Lower Bound & & & -0.63 \\
\hline Upper Bound & & & 1.43 \\
\hline
\end{tabular}

8- How likely it is that you continue your higher education at Texas State?

\begin{tabular}{|l|c|c|c|}
\hline \multicolumn{2}{|c|}{ Pre } & Post & Difference \\
\hline Average & 6.54 & 7.40 & 0.85 \\
\hline Standard Deviation & & & 0.63 \\
\hline $\mathrm{t}$ & & & 4.17 \\
\hline Lower Bound & & & -0.45 \\
\hline Upper Bound & & & 2.16 \\
\hline
\end{tabular}

9- How likely it is that you continue your higher education in the field of science (Mathematics, Chemistry, Physics, Biology) or engineering?

\begin{tabular}{|l|c|c|c|}
\hline & Pre & Post & Difference \\
\hline Average & 8.13 & 8.60 & 0.48 \\
\hline Standard Deviation & & & 1.36 \\
\hline $\mathrm{t}$ & & & 4.17 \\
\hline Lower Bound & & & -2.37 \\
\hline Upper Bound & & & 3.32 \\
\hline
\end{tabular}

10- How likely it is that you continue your higher education in the field of manufacturing engineering?

\begin{tabular}{|l|c|c|c|}
\hline & Pre & Post & Difference \\
\hline Average & 5.31 & 6.23 & 0.92 \\
\hline Standard Deviation & & & 3.06 \\
\hline $\mathbf{t}$ & & & 4.17 \\
\hline Lower Bound & & & -5.46 \\
\hline Upper Bound & & & 7.30 \\
\hline
\end{tabular}




\section{APPENDIX D: Answers to qualitative question in pre-research camp surveys}

- I don't really know that much.

- $\quad$ Manufacturing Engineers work in planning + constructing various things

- I fairly understand what engineers do, but I would like to learn more. I think engineers are mainly problem solvers.

- What my knowledge of engineers is that they are the ones who go the extra mile and do tougher work then the norms.

- $\quad$ I know very little. But I've worked in construction before.

- I am unfamiliar with the functions and tasks of the manufacturing engineers. Though I have a keen interest this field and hope to learn more

- $\quad$ Engineers built and construct a large of item, from bridges, to highways to an abundace number of tool to help improve our lives

- My understanding about engineering is that they perform task such as building, creating designs, and planning out things that will be created.

- They do a lot of modification and have an understanding of technology and its applications

- $\quad$ I have no understanding whatsoever

- $\quad$ I'm not entirely familiar with manufacturing engineers, but I do know engineers play a huge part in building anything

- I have some understanding but not much

APPENDIX E: Answers to qualitative questions in post-research camp surveys

1- Would you recommend this to other friends? Yes/No

$100 \%$ answered "Yes"

2- $\quad$ Would you participate in similar camp (in different engineering areas) in the same format of this camp? (1=No way $10=$ Absolutely)

Average answers: 8.85

3- $\quad$ Tell us about this research camp. How did you like this research camp?

- $\quad$ This was a very fun learning Camp thanx a lot.

- This is a learning experience

- This camp is an experience to does that are the engineering type.

- I learned a lot, had a great time, and want to do it again. It really opened my eyes to a whole new list of things I enjoy doing as a job

- I really enjoyed this opportunity to learn more about engineering careers and participate in a hand-on project with other members. I enjoyed learning and could say that this program was great and definitely not a waste of time.

- $\quad$ I would most certainly like to pursue a career in the field of Engineering, with much in Mathematics and Physics. A career in a broad field in Engineering/Business.

- $\quad$ I liked it $\mathrm{b} / \mathrm{c}$ it gave me an experience and outlook on the engineering work. Also it taught me teamwork.

- I really enjoyed it, and was honored to be a part of this camp. I learned many new skills, and procedures.

- $\quad$ I like the opportunity to use machines that cost 8,000 dollars for free.

- This program was a great experience for anyone that would like to know what engineering is about. The staff was very friendly.

- $\quad$ This camp gave me the opportunity to learn about the engineering department and what they do. It was a good experience and I would recommend it to anyone.

This research camp allowed me to gain information about a future vocation which I may pursue. I enjoyed the experience and had immense fun, and would hopefully like to continue with these applications. 
- $\quad$ Comment by their teacher: Overall, the students were quite involved. They, without a doubt, learned in many ways, many things. The learning would extend from technologies through team cooperation including self-responsibility.

4- Based on your research experience of this camp, describe your understanding about the functions and tasks of the manufacturing engineers and engineers in general.

- $\quad$ Crystal clear

- $\quad$ The functions for manufacturing are to keep the world going with bridges and stuff like that.

- $\quad$ Every step is critical, don't run stress analysis + it can kill you. Engineers have an awesome job

- At first I had a small understanding of what engineers did. I knew of aerospace engineering and how engineers created designs and built things but after this experience I discovered more careers in the engineering field in which I would like to consider now.

- $\quad$ An enjoying field and yet educational but learned a lot as well. Learned thoroughly about engineering and most of its fundamentals.

- $\quad$ In engineering you have to have good science and good math experience.

- $\quad$ I feel I better understand the tasks and functions as a whole. Also I know have an Idea what kind of field I would like to go into.

- The manufacturing engineers build specific parts and other things. They also test objects and work with machines to develop prototypes.

- $\quad$ I have a feel for the steps of how engineers do things.

- I have grasped the concept of engineering and how the people work.

- $\quad$ Engineers, as I see it now, are behind the scenes of nearly everything. From building bridges to musical equipment, engineers have a diverse range of tasks and jobs. The world would not function without those guys. 
NOTES 